ПЕТРОВ Вячеслав Константинович - кандидат философских наук, главный редактор сайта «Политическое образование», заместитель руководителя Школы молодого этнополитолога в Республике Башкортостан, РФ(vp230754@таil.ru)

ПЕТРОВА Марина Юрьевна - кандидат психологических наук, член редколлегии сайта «Политическое образование», соавтор программы экспериментального курса по подготовке оперативных сотрудников на основе компетентностного подхода в Академии ФСБ России (119602, Россия, г. Москва, Мичуринский пр-кт, 70; тр210260@таil.ru)

\title{
ОРГАНИЗАЦИЯ ИНФОРМАЦИОННЫХ ПОТОКОВ И УПРАВЛЕНИЕ ИМИ КАК НЕОТЪЕМЛЕМАЯ ФУНКЦИЯ АНАЛИТИКА
}

\begin{abstract}
Аннотация. Статья посвящена важности информационной работы аналитика в контексте рассмотрения информационной аналитики как «потоковой аналитики». Авторы рассматривают проблемы изучения информационных потоков, законы их формирования и управления ими, включая их тонкую настройку (модификацию, реорганизацию, адаптацию). Особое внимание уделяется изучению организации новых потоков, отвечающих задачам исследования, личного повседневного участия аналитиков в процессе сбора, обработки, индексации и первичного обобщения информации.
\end{abstract}

Ключевые слова: информация, информационный поток, информационная аналитика, аналитик

B своей предыдущей статье нами был поднят вопрос о пересмотре подходов к обучению профессиональных аналитиков. Проблема эта - многогранная, охватывающая все аспекты его деятельности [Петров, Петрова 2020]. И речь идет не только об изменении самой парадигмы в обучении, но и ее содержательной стороны.

К сожалению, изучение программ многочисленных курсов и редких учебных пособий по аналитике свидетельствует, что из поля зрения обучающих незаслуженно выпал ряд важных функциональных задач, которые, по нашему мнению, должен решать аналитик при производстве нового знания (научная составляющая) и выработке вариантов решений (практическая составляющая). Многолетний опыт аналитической работы подтверждает, что без овладения методами решения этих задач сложно преобразовывать информацию как таковую в знания, т.е. в данные с высоким уровнем достоверности, релевантности и актуальности.

Принято считать, что аналитическая деятельность включает в себя три компонента: владение аналитическими методами (функциональный компонент), знание предметной области (отраслевой компонент) и определенный тип структуры личности (личностный компонент) [Сляднева 2001]. При этом упускается из виду, что в век современных информационных технологий (СИТ) сама аналитическая деятельность претерпела кардинальные изменения. Из инструмента практической философии она стала действенным инструментом преобразования действительности [Курлов 2011]. Сегодня это уже не просто аналитика, а информационная аналитика.

Казалось бы, в самом названии - информационная аналитика - кроется какая-то избыточность. В самом деле, аналитика опирается на информацию и без таковой существовать не может. Признание информационной сущности современной аналитики далеко не случайно. Информационная аналитика, если можно так выразиться, это «потоковая аналитика». Это закономерный результат формирования «пространства потоков» [Кастельс 2000], 
которое усилило связность процессов и явлений, сделало ее всеобъемлющей [Коннектография... 2019]. А следовательно, изучение информационных потоков, законов их формирования и управления ими становится насущной потребностью всех субъектов информационно-аналитической деятельности. В отличие от других субъектов, только для аналитика информация выступает и как объект познания, и как средство социального управления.

Следует признать, что в последнее время наметилась устойчивая тенденция отхода аналитиков от непосредственной работы с информационными потоками. Они передали эту функцию, как сегодня модно говорить, на аутсорсинг разного рода структурам, специализирующимся на выполнении информационных заказов. Сказывается ли это на качестве анализа и подготовки соответствующих аналитических материалов? Безусловно. Ведь аналитики лишают себя возможности контролировать процесс сбора информации, а следовательно, возникают проблемы с оценкой ее объективности и полноты. Согласитесь, кому как не аналитику, изучающему явления, события и процессы, вырабатывающему проекты управленческих решений, нужно в первую очередь озаботиться этим. Из его поля зрения выпадают целые этапы работы с информацией, игнорируются ключевые принципы информационной работы, в частности определение терминов проблемной области, до конца понятных только самому аналитику 1 .

Отчасти к этому ведет сложившееся разделение участников единого информационно-аналитического процесса на аналитиков и так называемых информационщиков. И это не условное, а самое реальное размежевание, сказывающееся на уровне взаимодействия, формирующее разный статус участников данного процесса. Раздельная подготовка и переподготовка аналитиков и информационщиков однозначно вредит делу. Ведь информационщики должны ясно представлять специфику работы аналитиков, понимать, какую информацию и в каком виде они должны представить. В свою очередь, аналитики должны представлять, что им могут дать информационщики и соответственно формулировать к ним свои требования. В противном случае теряется прагматический смысл информации (возможность ее эффективного использования), являющийся объектом информационного анализа, заключающийся в том, что ценность информации зависит от соответствующей ситуации и от уровня тезауруса субъекта информационно-аналитической деятельности. Только взаимопроникновение ее субъектов в процесс деятельности друг друга позволяет достичь главной цели информационно-аналитической деятельности - получения не просто информации как таковой, а знания - информации с высоким уровнем достоверности, релевантности и качества для выработки адекватного управленческого решения.

Даже при условии непосредственного и активного участия аналитика в процессе сбора и обработки информации львиная ее доля сегодня приходится на так называемую вторичную информацию, т.е. информацию, которую кто-то и когда-то разместил в информационном пространстве. Проследить весь ее путь от первоисточника, который зачастую остается невыясненным, к потребителю крайне трудно или невозможно. Отстраненность аналитика от сбора и первичной обработки информации ведет к тому, что информация становится уже не вторичной, а третичной и т.д.

${ }^{1}$ В идеальной технологической цепочке анализа (особенно это касается сферы политики) за определением (постановкой) и оценкой целей и задач анализа (прогноза) следует этап сбора, обработки, индексации и первичного обобщения информации. И только после этого - анализ, синтез, построение логических цепочек, обобщение тематических массивов информации. 
Как здесь не вспомнить так называемые законы информации, сформулированные каким-то острословом, но точно отражающие суть вопроса:

- информация, которая у вас есть, не та, которую вам хотелось бы получить;

- информация, которую вам хотелось бы получить, не та, которая вам на самом деле нужна;

- информация, которая вам на самом деле нужна, вам недоступна;

- информация, которая в принципе вам доступна, стоит больше, чем вы можете за нее заплатить.

И это объективная повседневность, с которой сталкиваются аналитики.

С чего начинается любое исследование? На практике - с выявления и формулирования проблемы, построения информационной модели изучаемого объекта, изучения имеющихся информационных потоков с точки зрения их применимости (качество и полнота циркулирующей в них информации). С точки зрения информационной аналитики под информационным потоком мы понимаем совокупность информации, перемещающейся в информационном пространстве по каналам коммуникации. С точки зрения управления он представляет собой совокупность циркулирующих в системе, между ней и внешней средой сообщений, необходимых для принятия управленческих решений, анализа и контроля за деятельностью анализируемого нами объекта.

Можно с уверенностью утверждать, что в каждом конкретном случае существующих информационных потоков недостаточно. Возникают проблемы организации новых потоков, отвечающих задачам исследования, и тонкой настройки (модификация, реорганизация, приспособление, адаптация) уже функционирующих. При этом важно соблюсти одно условие: для формирования управленческих решений на основе анализа совокупности разрозненной информации важно иметь для этого запас времени. Другими словами, избыточность информации так же вредна, как и ее недостаточность. И здесь мы подходим к проблеме выработки механизма отбора релевантной информации, овладения им аналитиками.

Собственно, этот механизм зависит от того, с какими информационными потоками работает аналитик - с теми, в которых некая информация уже зафиксирована (формализована), или с теми, в которых информация циркулирует по каналам неформальной коммуникации (по этому признаку в спецслужбах принято подразделять информацию на разведывательную и оперативную).

Выбор источников информации - это отдельная тема, которой мы намерены посвятить один из следующих материалов. Здесь же отметим некоторые из них. Это открытые источники - СМИ, научные (экспертные) публикации, сведения о конфликтах (в политической сфере это самый полезный и порой наиболее точный источник информации) и только в последнюю очередь - Интернет.

К вышеперечисленным следует добавить массивы информации - подшивки, подписки, архивы, отчеты, аналитические подборки (самый надежный способ сбора информации).

Отметим, что алгоритм поиска и обработки каждого из этих источников имеет свою специфику. Что касается сетевых ресурсов, то надо четко понимать, что большой массив информации - это не всегда хорошо, продуктивность поиска в Сети уступает другим источникам информации. Тем не менее при наличии опыта рациональной поисковой работы в Интернете можно выискать что-то полезное для своего исследования. Интернет - это хороший коммуникационный канал для связи с наиболее профессиональными информационными порталами и СМИ.

Но на практике самым эффективным способом сбора информации является общение с экспертами, участниками (или наблюдателями) анализируемых 
событий (в политической аналитике в качестве таковых выступают коллеги по цеху, журналисты, политики, чиновники и т.п.).

При этом в целях минимизации временных и ресурсных затрат на получение нужной информации каждый из выявленных устойчивых информационных каналов исследуемого объекта должен быть описан с точки зрения объема циркулирующей информации, ее содержательности, полезности для анализа, определен способ его использования в решении поставленных задач (доступ к информации, овладение ею). Это прерогатива аналитика, его прямая обязанность, если, конечно, он заинтересован в качественном анализе.

Фактически речь идет об организации аналитиком информационных потоков и направлении их на себя, по возможности, «очищенных» от второстепенной информации (так называемого белого шума), отвлекающей внимание и ресурсы. При этом сложность этой работы заключается не в технологии выработке стандартных процедур, которые хорошо известны [Гордукалова, Юдина 1991], а в организационной дисциплине. Если аналитик не сможет заставить себя ежедневно уделять этому внимание, не привыкнет на регулярной основе встречаться как минимум с одним экспертом, не возьмет себе за правило посещать публичные мероприятия, входящие в сферу его профессиональных интересов, то он не может рассчитывать на глубокий анализ, а следовательно на серьезных заказчиков. Кстати, этим и отличаются продвинутые «фабрики мысли», делающие упор на работу с экспертами; так должны функционировать и ситуационные центры.

Возвращаясь к механизму отбора релевантной информации, важно отметить проблему освоения аналитиками методов и приемов, используемыми в конкурентной (деловой, экономической) разведке [Ющук и др. 2019]. Это формирование так называемых поисковых роботов на основе досконального знания языков поисковых машин, их грамотная настройка (актуализация), т.е. чуткое реагирование на все изменения информационного фона путем внесения коррективов в конструкцию «роботов». При этом поисковые запросы из разовых превращаются в действенный инструмент аналитика, получающего возможность моделирования своего индивидуального рабочего места.

Активное применение «поисковых роботов» вынуждает аналитика освоить работу с тезаурусом (словоформами), тем самым глубже проникнуть в суть анализируемых объектов или явлений, построить их адекватную информационную модель.

Еще раз подчеркнем, что без повседневной кропотливой информационной работы аналитику трудно достигнуть высокого уровня знания в своей предметной области как «постоянно изменяющейся смеси полученного опыта, оценок, информации, экспертной проницательности и природной интуиции, которая дает возможность оценивать, перерабатывать и использовать новый опыт и информацию» [Галущенко 2009]. Мы исходим из понимания того факта, что не существует каких-то особенных приемов легкого получения необходимого сырья для аналитической работы, а есть только рутинная работа. Безусловно, с опытом аналитики нарабатывают информационные связи, полезные контакты, любимые приемы и дополнительные возможности, но (еще раз подчеркнем) это никак не связано с некими «тайными знаниями», а является результатом каждодневного упорного труда.

Статья подготовлена при финансовой поддержке Российского научного фонда, проект № 17-78-20149 в рамках работы Школы молодого этнополитолога в Республике Башкортостан. 


\title{
Список литературы
}

Галущенко О.В. 2009. Информационно-аналитическая деятельность в современном обществе. - Известия вузов. Северокавказский регион. Общественные науки. № 3. С. 5-8.

Гордукалова Г.Ф., Юдина Л.А. 1991. Мониторинг документального потока для информационной диагностики прогнозируемых объектов: учебное пособие. М.: ИПКИР. 107 с.

Кастельс М. 2000. Информационная эпоха: Экономика, общество и культура. М.: ГУ ВШЭ. 606 с.

Коннектография. Будущее глобальной цивилизации (пер. с англ. Э. Кондуковой). 2019. М.: Манн, Иванов и Фербер. 432 с.

Курлов А.Б. 2011. Становление аналитики как инструмента практической философии. - Вестник Академии экономической безопасности МВД России. № 7. C. 9-20.

Петров В.К., Петрова М.Ю. 2020. О новом подходе к подготовке профессиональных аналитиков. - Власть. Т. 28. № 3. С. 17-23.

Сляднева Н.А. 2001. Информационно-аналитическая деятельность: проблемы и перспективы. - Факт: электронный информационно-аналитический журнал. № 2. С. 14-25.

Ющук Е.Л., Пелевина Н.А., Сергеев К.В., Ющук В.Ю. 2019. Конкурентная разведка: маркетинг рисков и возможностей. 3-е изд., доп., пер. Екатеринбург: ПервоГрад. 264 с.

PETROV Vyacheslav Konstantinovich, Cand.Sci. (Philos.), Editor-in-Chief of the website «Political Education», Deputy Head of the School of Young Ethnopolitologist in Bashkortostan (vp230754@mail.ru)

PETROVA Marina Yuryevna, Cand.Sci. (Psych.), member of the website «Political Education» Editorial Board, co-author of the pilot course on training operational officers based on the competence approach in Academy of the Federal Security Service of the Russian Federation (70 Michurinsky Ave, Moscow, Russia, 119602; mp210260@mail.ru)

\section{ORGANIZATION AND MANAGEMENT OF INFORMATION FLOWS AS AN INTEGRAL FUNCTION OF THE ANALYST}

\begin{abstract}
The article is devoted to the importance of the analyst's information work in the context of considering information analytics as flowing data analytics. The authors consider the problems of studying data flows, the laws of their formation and managing them, including their fine-tuning (modification, reorganization, adaptation), and pay a special attention to the organization of new flow that meets the research goals, analyst's personal daily participation in the process of collecting, processing, indexing and primary generalization of information.
\end{abstract}

Keywords: information, information flow, information analytics, analyst 